\title{
Wellbeing as a Key Site for the Encounter Between Arab-SPeaking Refugees And Austria
}

\author{
Leonardo SCHוсchet, Institute for Social Anthropology, Austrian Academy \\ of Sciences, Vienna
}

\section{CONTENT}

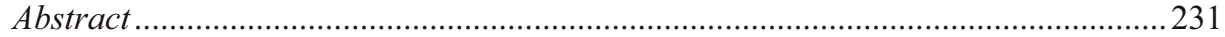

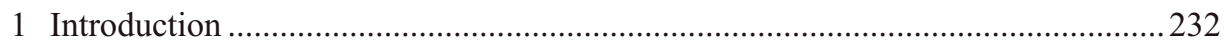

2 Outlining Wellbeing among Arab-Speaking Refugees in Vienna ..........................2234

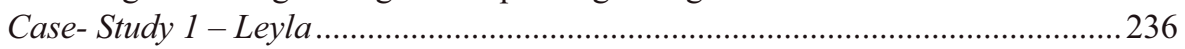

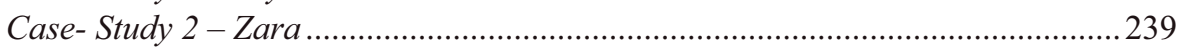

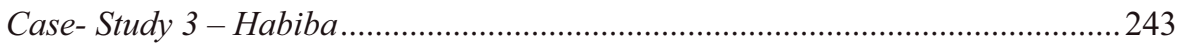

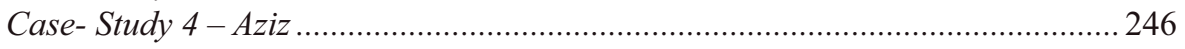

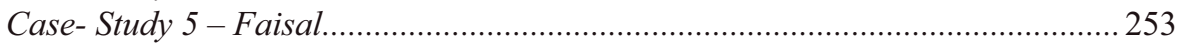

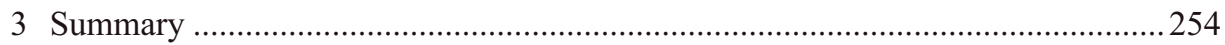

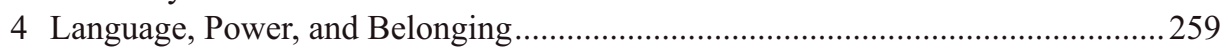

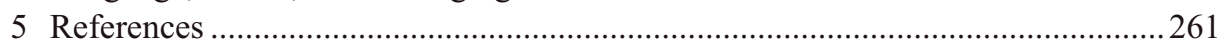

\section{Abstract}

In the LODA interviews, Arab refugees have expressed to a great extent concerns and expectations about their lives that were important to them. Much of it echoed through most of the interviews, and it is important that we are aware of them for research and policy purposes alike. These expressions were highly coated in a cultural idiom that may or may not be translatable to Western (and WHO) conceptions of wellbeing. This paper presents these expressions, pointing to potential similarities and differences with English notions of wellbeing circulating in the current academic discussion on the term. This paper is to be followed by a more analytical one, discussing if cross-cultural comparison on wellbeing is even possible and, if so, how useful it would it be as a research tool and how academicians could go about it. 


\section{Introduction}

Research on wellbeing has started in the late 1960s and has been gaining traction since the 1990s. Researchers are particularly interested in how to measure wellbeing. However, one first needs to know what is being measured. Scholars have noticed that theory-based perspectives are conspicuously absent (RYFF \& KEYES, 1995) and how wellbeing should be defined and measured are two questions that remain largely unresolved (DoDGE et al., 2012).

The World Health Organization (WHO) defines health as "a state of complete physical, mental and social wellbeing and not merely the absence of disease or infirmity" (WHO, 2006, p. 01), which may be interpreted as stating that health is the absence of suffering. However, many are those challenging this definition today. James Larson (1996) contends that the WHO formulated this definition in 1946 - after World War II when the social health of societies was a main topic in public discourse, and that, more recently, American social scientists have questioned a definition "that requires complete health" (1996, p. 181). Among those proposing alternatives, HuBER et al. (2011, p. 01) suggest defining health as "the ability to adapt and self manage in the face of social, physical, and emotional challenges."

DODGE et al. assess the history of the academic debate on the topic and propose a new definition of wellbeing, up to date and all-encompassing of important fragments present only in one or the other definitional trend. Already from a culturally sensitive perspective based on individual's self-assessment they conclude that "it would be appropriate for a new definition of wellbeing to centre on a state of equilibrium or balance that can be affected by life events or challenges" (DoDGE et al., 2012, p. 222). However, for these authors, wellbeing is not a construct, but "should be considered a state - a condition of a system in which the essential qualities are relatively stable' (REBER, 1995, p. 750)" (DodGe et al., 2012, p. 226). They define wellbeing thus "as the balance point between an individual's resource pool and the challenges faced" (DoDGE et al., 2012, pp. 229230). However, this definition still embodies some of the main limitations in defining and measuring wellbeing. The most glaring limitation is the idea of homeostasis, or that individuals perceive and strive for equilibrium, which in as much as it is thought as relative to individual, it is still farfetched because it depends on measuring "normality" and equating it with affluence (SAHLINS, 1972), which individuals may never achieve or define for themselves. Wellbeing can be an idealized concept, but it can also be out of someone's phenomenological field, and thus may not be neatly measured in practice.

But wellbeing, perhaps even more than health, is a concept that inherently relates to the realm of subjects' own experiences. And if health is to be defined through wellbeing as the WHO contends, and if wellbeing depends on managing the self as HuBER et al. propose, then one must acknowledge how culture and context shape health. 82 years after 
the original WHO definition of health, the world is again facing a huge crisis of human displacement, and understanding health and wellbeing among displaced subjects is paramount. This paper considers the encounter between Arab-speakers coming from the Syrian and Iraqi conflict - thus greatly affected by violent displacement, dispossession, and war - and the Austrian context, highlighting the points of view of this heterogeneous group of displaced Arab-speakers. It is based on participant observation and 60 in-depth interviews with displaced persons (refugees or asylum seekers) coming from the Syrian and the Iraqi conflicts, which is part of the broader LODA project presented in this volume. ${ }^{1}$ So, while the LODA results include material on refugees from the Afghan, Syrian, and Iraqi conflicts, this paper considers only the experience of Arab-speakers, for it reflects on the extent that language shapes/is shaped by shared conceptions and experiences. Not all interviewees answered every question asked, but all of them at least gave broad statements about the core questions composing each research cluster of the survey. Finally, while this paper concerns one specific research cluster, denominated in LODA "wellbeing," many of the excerpts I present here were brought about when the interviewees were either answering questions that were not directly related to this research cluster or simply expressing what they thought was important to mention about their experiences of flight and their encounters with their Austrian hosts.

The displaced Arab-speakers and their Austrian hosts have not always found a common "language" and agreed on ways to deal with these questions. Thus, this paper focuses on conceptions of wellbeing and health as a perspective through which a common understanding can hopefully be reached. This is so because refugee expressions of their own situation are deeply marked by displacement and the social processes displacement generally entails. I argue that, in the context of the displacement of Arab-speaking refugees to Austria, as it would be in other similar contexts, social belonging tends to be greatly perceived and expressed as an issue of wellbeing, defining individual and social health and individual and collective capacity to engage productively with society.

Some of the expectations about the encounter between Arab-speaking refugees and their Austrian hosts - two heterogeneous yet often fairly discernible groups of social actors - can be surprisingly similar. Yet, mental distress, including but not limited to depression and trauma, is not only often expressed in different ways, but is also often experienced differently and seen as prompting different kinds of engagements. While the jargon produced and mobilized by Austrians emphasizes the need for "social integration", national economic security, and the maintenance of cultural identity, the displaced Arab-speakers have typically expressed their need for social understanding,

While all 60 interviews are considered, examples will be brought mainly from a subsample of 30 interviews conducted by myself. While some interviews took more than 4 hours and were very much open-ended, these interviews typically lasted in average from 1 hour and 10 minutes to 1 hour and 40 minutes, and while some interviewees chose to speak a mix of Arabic and English, almost all of them were conducted only in Arabic, without an interpreter or any other form of mediation, and followed a semi-structured script forming the LODA survey applied to all displaced respondents. This means that, while a set of core questions was asked to all interviewees, each interviewee was also free to express themselves in whatever topic they chose freely. 
respect, and a chance to participate and be productive in the host society, as the interview excerpts I will present demonstrate.

In what follows, I present ethnographic evidence of how Arab-speaking refugees who arrived from the Syrian and Iraqi conflicts in Vienna have understood and expressed their main concerns in exile in terms of wellbeing, and explore the specificities of the underlying conceptions. The general concerns, expectations, fears, affects, and dispositions discussed here will then be organized in the form of a general conceptual outline of these refugees' perspectives.

The reader must be aware that this paper is only my first effort in compiling and analyzing LODA's material on wellbeing, and it's thus best understood as an "analytical report" more so than just an empirical report or a more theoretical piece. This is so because it first and foremost aims to showcase LODA's empirical material on wellbeing instead of discussing it in light of the academic literature on the subject, while already tailoring this empirical material to engage the $\mathrm{WHO}$ principle that health must be defined through wellbeing.

\section{Outlining Wellbeing among Arab-Speaking Refugees in Vienna}

This section builds up to a tentative frame to explore different conceptions of what is called "wellbeing" in English, given that the interaction between host state (Austria), humanitarianism, and refugees causes a conceptual attrition that, in turn, generates hindrances to the refugees' permanence in Austria.

Throughout my fieldwork in the Arab world and around Arab communities of refugees and migrants in the Middle East, Latin America and Europe (2006-2018), I learned that mental health in the Arab world at large tends to be understood and managed in ways that can significantly differ from what European medicine and the disciplines of the mind generally prescribe. Thus, even in Austria one can already often find taboos related to acknowledging certain forms of psychological distress and even more so to seek council or treatment; in the Arab world some these taboos tend to be more pronounced. However, the taboos which are more pronounced in the Arab world than in Europe are not necessarily about being diagnosed with, or recognized as having, a mental illness, but about seeking the council of a professional specialized in the psyche. This does not mean that Arabs in general are more prone to having more taboos about those considered to be in psychological distress than Europeans do, but only that being clinically labeled with a psychological disorder and undergoing clinical treatment in the Arab world have been historically more uncommon than in Europe, and thus are considered extreme and often odd. The LODA material I present here corroborates this point. 
In what follows, I will first track a few individuals in greater depth not only to give the reader a better sense of the contexts from which I extract the main points of my analysis, but also to bring the reader a richer approximation to the data produced by LODA, so they are able to produce their own original insights or better ponder about my own analysis. This strategy is in line with the overall objective of this publication, which is to showcase some of the main conclusions of the LODA study along with presenting the data itself and making it available to a wider public. These sections will be called "case studies" for the lack of a better term. However, readers should not necessarily make sense of the interview excerpts I present below as if a master narrative or moral of the story could be taken from each one of them. Instead, I present these different excerpts so the reader is aware of when a given interviewee mobilized an expression of mental health state, so each excerpt should be understood only as providing some context to the expression(s) it presents. Then, I will proceed by highlighting a few key topics and expressions of state of mental health of these case studies and present further evidence about them through quotations taken from other interviews composing the sample. Having brought about the necessary evidence, I will finally make a general case about how my interviewees conceive and express wellbeing in relation to their situation in Austria, which is why they should be taken into consideration when engaging displaced Arab-speakers through both civil and policy actions.

In tandem with this more ethnographic and data presentation piece, I am also preparing a forthcoming publication geared towards discussing conceptions and experiences of wellbeing among Arab and Arab-speaking displaced persons in Austria in relation to the state-of-the-art literature on the anthropology of forced migration and health at large. While in this present paper I engage almost solely with the data produced by LODA, it is in this second incoming publication that the reader can expect a dialogue with the state-of-the-art bibliography on medical anthropology and wellbeing and forced migration. In addition, the LODA team is also concomitantly publishing a best-practice/ policy paper to which I contribute practical ideas stemming from the analysis here presented. In other words, this paper proposed only a diagnosis of the social situation analyzed, while prognosis (policy recommendations) will be incorporated in another collective publication by the LODA research team. Readers more interested in one or another are advised to search for those publications.

One of the principles of LODA's research design was to capture the diversity existent among these displaced Arab-speakers as much as possible. Thus, this research contains a fairly good rate of gender, ethnic, religious, generational, social class, and even national belonging cleavages. ${ }^{2}$ While this does not allow LODA to make assumptions based on specific ethnic or religious groups, it allows for a broad understanding of this heterogeneous group at large, while perhaps also allowing for some insight on the

2 This is so because many of the interviewees would not unproblematically identify themselves as Syrians or Iraqis, given that some were of Palestinian, Kurdish or Circassian origin, for example, or may have been born elsewhere but were nonetheless considered refugees or asylum seekers of the Syrian or the Iraqi conflict by the Austrian authorities. 
specific situation of this group based on gender. This question of representation has informed my choice of interviews and quotations I present in what follows.

\section{Case Study $1-$ Leyla $^{3}$}

Leyla is a 48-year-old Syrian woman. She is divorced and is a Shi'i Muslim. She was accepted as a refugee in Austria, where she has been living since January of 2016.

I arrived in Austria in 2016 and I didn't like it.

Me: No? why?

Her: Didn't like it at all.

Me: Because of the weather?

Her: No, Austria was for me the first ghurba [estrangement $\left.{ }^{5}\right]$. Despite having lived in Egypt, Beirut, and Istanbul, I didn't get this feeling. In Austria, I felt my first estrangement. I got depressed. I am sick with depression and I take medicines. I had an appointment with the doctor yesterday and he gave me medicines. I felt myself helpless in Austria and I cannot do anything. So, I entered this depression mood. I don't like to go out of home and see or talk to anyone. Any place my daughter would take me to, I feel it is not nice. I didn't feel interested with beauty or nature. Of course, I went to doctor and he gave me treatment. But it seems that I should control this from inside. I am the one who needs to deal with this question. My friend [cited a name] who was with you 2 days ago, if you remember her. She tried and got tired with me. Because she was before me, so she tries to take me out but I don't have any power. It didn't work. Then, I felt that I missed my writing. I feel I am stranger in Vienna; I don't feel myself here. Some good periods pass and I can find myself, but other periods not. I can never find myself.

Me: Can you describe a typical day for you in Austria?

Her: I do my house work and food. My daughter who lives with me, she would be in the course. In the morning, she takes her son to the kindergarten. She comes

3 All names cited here are fictitious so as to preserve the interviewees' identity and security. 4 Contiguous lines indicate contiguous flux of conversation, while a skipped line indicates that the excerpt was taken from another point in the interview. For example, while what surpassed in the first excerpt may have started at around 4 minutes of the interview, what comes after the skipped line could have started at, for example, after 34 minutes of interview. The excerpts are presented in the original order of what was spoken during the interview. That is, if an excerpt comes before the other it is because it was spoken before the other.

5 The full meaning of this complex term will be developed towards the conclusions. 
back at noon. Of course, by that time, I could see if there is anything to be done at home. I could read despite not having the capacity to read anymore. But I try so my brain can still work. I read for about an hour, it is a must because of focusing. We eat at lunch time; I could sleep in the afternoon. I could go out but I mostly don't go out. I have this problem that I don't like to communicate with others and I don't like to see people a lot. And my day finishes like this. I enjoy my time with my grandson a lot. He gives energy to my life.

Me: Did you have expectations concerning work here in Austria?

Her: First, I didn't have the chance, and second, I don't have the power anymore. I can't write anymore. I... myself, cannot start to write. The problem is psychological, I mean, I don't have power/ability to write. (...) Even if I there is a job with muscle effort, I can't do it. I can't carry up and down, this is not my field and I don't have the ability to do it. That is why there is a problem in Austria for those who are older than 50. They can't easily work and this is causing a psychological crisis for people.

Me: Now I would like to know a bit more about wellbeing. But not only as physical health, but also psychologically. How do you feel in general about your life in Austria?

Her: My life in Austria doesn't have a meaning. Because I feel that I am not a productive person, a person who doesn't do anything. I am not doing anything in life and this is a very bad feeling. It is like I only eat, wake up, and if I have a course, then I go to the course and I come back. This is me in Austria. I have a problem with it. I don't feel that I'm doing anything for society. I don't feel I am present in anything. It is not that I don't want to.

Me: Do you feel a bit lonely? There is no people and life?

Her: I always feel lonely. But this could go away if I could do something. If I could go beyond the language barrier. Our problem is always the language. This could lead to any solution to any problem.

Me: Did you have experiences with the health system here in Austria? Like a hospital or a doctor?

Her: I didn't go to hospital, but I went to a normal doctor. I saw a health doctor, and a psychologist. [the doctor gave her medicine, so it's likely a psychiatrist, regardless of what she calls it]. (...) This is what I am feeling. It is really difficult. You must have capacity to go here and there.

Me: Do you feel positive concerning your future here in Austria? 
Her: If I want to talk from my mind, yes. Austria is better. But from my emotions, no.

Me: Do you feel positive concerning your future here in Austria?

Her: (...) You got the idea, I mean the brain stops. I like my country and I want to go back! No, this is not right. But logically, as illness and health insurance, all these are not found in Syria.

Me: What if the problem is inside you?

Her: If the problem is a feeling, it often doesn't have a solution.

Me: When you feel sad, this is also a problem.

Her: I had this all the time. If you met me 4 years ago, you wouldn't believe this is me. I am among those who like life a lot. I like to swim so much. I have the ability to create happiness in any place I am in. No, I am not like this. Now I am more into silence, it is rare to feel happy and laugh. It is not that easy. Of course, the sadness I am living in, I know its reasons. Because I left my country and my house and my friends. I left everything. It is like a plant or a flower that you took and plant it in a completely different soil. It would live of course.

Me: But won't be strong.

Her: Now I am not strong. I am brittle inside. Anything could make me cry. If I see a small child in the street crying, I would cry. I wasn't like this. And this is what made me go to a psychological doctor. Of course, he helped me somehow; he gave me medicine and talked to me. But my problem is inside. I would like to live and be happy, but I can't.

Me: So you should change this situation...

Her: Yes, my problem is that I am not finding myself in the right place. I feel this is not my place.

Me: You mean you feel disenfranchisement [ghurba]?

Her: Yes! Ghurba! It doesn't have a medicine, or a doctor. Yes, exactly, I have ghurba and this is affecting everything in me. You know what? Sometimes I wake up and I see my tears going down. I don't know why. I don't know what I had seen.

Me: Do you have anything to tell Austrian politicians? For example, to make the lives or services better for the refugees?

Her: (...) But from 2013 until 2017, and the beginning of 2018, the situation had broken down so much. A lot of people died, some people lost their families 
in front of their eyes. This person is not psychologically normal. When they come here and others are cruel to him, something wrong is going to come out of him.

Me: What are your plans and expectations for your future? What are your plans and expectations for the future of your children?

Her: In general, my daughter, with whom I live, likes Vienna so much. She is so integrated in society, and she likes the country so much. I see that my daughter's future is here. But as for myself, to be honest with you, I don't see my future here. I feel that I want to go back to my country. The first feeling I always have is that I want to return to my country. Of course, reality says no according to what is happening. Syria is not available for me to live there. Safety conditions and daily life. The currency is very weak. My mind says that my future is in Austria, but my emotions say that I can't continue in Austria. So, I am living this conflict and I don't know where it would lead me. This is the reason of my inside problems. I always say a simple word; I want to die in my homeland. I don't want to die in Vienna.

\section{Case Study 2 - Zara}

Zara is an Iraqi young woman of 24, single, who arrived in Austria in February of 2016 and is still an asylum seeker. She has already been refused asylum once, appealed, and is still waiting for a positive answer. She came with her older brother to Austria, but she lives with a friend of Egyptian origin and Austrian citizenship and her friend's child. She is of Sunni Muslim origin but defines herself as atheist and claims she has little tolerance for religious moral discourses about how she should conduct her life.

Me: How is your typical day in Austria?

Her: [English] And I translate, before I started translating for money with the Queer Base, I was also translating for people for free. I translate mostly in the hospitals because [Arabic] the official facilities [English] in Austria, they don't speak English. They only speak "Deutsch," and I don't. So, mostly I go with my friends, the Arabic people I know, who needs like someone to go with them to the university, someone to take them to the [mentions two organizations] so I am always busy. And also, I have my best friend, she has a 5-year-old, she spends like six days of the week with me, we co-share our "raising" [child rearing] and I try to stay at home and not leave the house because I am constantly out. 
Me: You are tired, you mean.

Her: Yes!

Me: Of course.

Me: Who are your main social contacts in Austria?

Her: [English] It's mixed. I have lots of Austrians friends, and I have lots of Arabic friends, but because I am really busy, I have a busy schedule, I try to have my contacts with only, like, the people I have something to do with them (...) we are doing something valuable.

Me: What are the main questions and challenges you face in your everyday life?

Her: In relation to me, the most important thing is the "Deutsch" question. [English] But I don't speak Deutsch. I am not actually learning it. I just think about it. So it's a big problem. I think that if I had Deutsch too, I would die, because then I would really have no time.

Me: OK, now in relation to wellbeing. What influences the most your life in Austria, and your actions here?

Her: Frankly, I mean [English] first of all I am a woman, so, in a normal situation we have our ups and downs [Arabic] but here, when you are, secondly, a refugee, your situation is stretched. So, there are days when you feel good, there are days when you feel not good. There are days no one knows me and days I am comfortable and I don't think a lot. I do many things, and there are days I cannot do anything. And days I don't leave anything empty (...) [English] only, emotional support. [Arabic] My situation is not going to do me anything, but sometimes the words disappear. [English] Emotional support, [Arabic] all these things, [English] it counts. I was really depressed, especially when I was in Bad Goisern. [Arabic] I feel now here [English] content. [Arabic] Even about the papers I don't think about them much, but I think it does not move to me. And I have a family, my mother, my sisters. So, I think about these things. When I was on my own here I was relieved, my family would not think, they were well, when I will get the papers.

Me: Personally, is there something troubling you?

Her: There is nothing [English] in particular. The subject of the papers only. The prejudice. But they didn't treat me [with racism] much here in Vienna. And you learn to deal with it. When you listen to a word that is not nice, even when you don't have German, you answer in English. Now, about 2 days ago, there was an organization called [mentions an institution], they called me asking if I could translate, really it was not nice. (...) My friend got depressed, she didn't return to the Deutsch course. She went to the psychologist. How do you want her to translate like this? He was really bothered from me, because of the translation. 
Me: This term, depression, is important to me...

Her: Yes! I told him, she's depressed if she was well, I could bring her to you.

Me: OK, and did you have experiences with, eh, Austrian health care system, for example, doctors and hospitals? If so, how were they?

Her: I have a lot of experiences with the health system. In the field of psychology [English] therapy [Arabic] and hospitals. I went to all of them. Frankly, it is nice. Very nice. And the e-card is great.

Me: But your experiences with the system were through work.

Her: I translated to people, but I also went more than once to the [English] general doctors [Arabic] and [English] eye doctors [Arabic] good.

Me: Do you feel positive about your own future in Austria?

Her: There are days in which I am very enthusiastic. It will be like this, and this and this, and after 20 years it will be certainly like this. And there are days I ask myself why do I want to do this? Why do I want to learn Deutsch? I don't want papers. So... [English] It's ups and downs. I have my good days and my bad days.

Me: All of us, right?

Her: All of us!

Me: But for some this is more pronounced.

Her: Yes.

Me: OK. So, how do you overcome problems?

Her: [English] I used to drink [laughs]. But now I stopped. Occasionally. I talk to my mom. My mom is a great help in this case. And my brother is a great help. He is a little bit depressed person when you talk to him [laughs] but, because I am not alone. I have my brother. It is better than being here alone.

Me: Right!

Her: [English] It's a very strong connection. And I have friends, and these friends, they are, I made a circle of people I can trust, I can talk to, and I can have positive energy from them.

Me: And how important are your social contacts in this regard?

Her: A lot. [English] It's like therapy. When you talk to your friends it's like therapy.

Me: And to what extent do you think you spend your time in a valuable way?

Her: I try to spend all my time in a valuable way, I mean, [English] I try to be productive. I try to finish all the appointments that I have, I told you, actually, I 
don't go with people, like, they tell me, let's go sit in the Donau. I don't want to go sit there! Ok? The same person asked me to go and translate for him I say, ok, I come with you. I try to make it productive because at the end of the day, because I was having depression. So, for me, in the end of the day I have to think what I do. So, for example, today, when I come back, I will try to sleep, I will say, OK, this was a productive day, I finished the interview with Leonardo, I went in the morning to translate, and I made food, and I will go and wash my brother's clothes, and then I will go to [cites a name] to help with some things because she is searching for a place, so I'm happy, I'm content. Actually, the sad days are the Sunday and the Saturday. Because I have to sleep. I miss sleeping, then, now I am used to waking up in the morning, I used to sleep for 14 hours. Or, like, 20 hours per day. And I had no problem with it. So, I sleep a lot. And now, I went to Bad Goisern, I slept, because I was sleeping in my friend's house, so, I went to sleep at 10 at night, and I woke up in the next day at 1 o'clock in the afternoon. So, I have a problem with the holidays. So I try to always to make them full.

Me: So, whenever you are busy, you are happy, right?

Her: Yes. [English] And I work better under pressure. If you tell me let's meet whenever you have time we will never meet. But if you tell me, do you have time on Wednesday, yes we will meet on Wednesday.

Me: Are you comfortable here in Austria?

Her: I am comfortable. [English] But there is something I always say. No matter how much I live in Austria, how long I live in Austria, I will never be Austrian. I like many of the things they do, but I don't do some of these things and it just believes that I have principles, and the same way I felt in Iraq because I was feeling the same. Because I came from a liberal family, so I wasn't really fitting in, so I always didn't feel like I belong there, and now I will never feel I belong here, and I cannot be part of my society, and I cannot really be a part of this society, like I will be a part, but you will always be different. So, I will always be stuck in this middle.

Me: Yes. I understand.

Her: [English] But I was really depressed because of this, but now I am looking at it in a very positive way. Like I will always be unique. My ideas and my perspective will be different from other people.

Me: Right. And you? What do you expect from the Austrians?

Her: [English] Understanding. [Arabic] Frankly, I don't want anything from them, only, I'm human. I don't want people to focus to the way I talk. [English] I am so tired of being labeled as a refugee. 
Me: Is this related to that problem you told me, I mean, your depression?

Her: Yes, yes, yes. A lot. I, for example, I am, [English] I am so sick and tired of being labeled as refugee.

\section{Case Study 3 - Habiba}

Habiba is a 46-year-old Syrian Druze. She arrived in Austria in July 2015 and has lived in this country with her children while her husband lives and works in Lebanon. She and her family are all entitled to asylum in Austria.

Me: OK. What are your biggest challenges here in Austria?

Her: Proving my existence.

Me: The refuge issue?

Her: To prove yourself, who you are. To go out of a number status and into a human status. This is the most important thing.

Me: How did the expectations you had before change now? How did it change now for you as a refugee here?

Her: I don't see the beauty of the country anymore, I see how would I work, how would I prove my existence. How would I go through the language obstacle? We never learned a language before, even at school. Right now, anything I need, my kids have to translate for me. I feel that this is rough on me.

Me: Did Austrian organizations help you concerning housing or not?

Her: To wait. I lived in Austria for about 7 months, knowing that people here were so nice. But to walk from their house to the train station you need 20 minutes. At 11 o'clock, maybe, or 12. No there are no trains at 11 o'clock in villages. My kids want to go home from school, they live in Vienna. In the morning, the landlord would take them with him since his son is in same school. But on the way back home they come to Volkersdorf. Sometimes there are no taxis.

Me: Yes, there is nothing.

Her: Yes, no bus. And for me, there is no music, no theater, nothing. So I felt that I couldn't breathe. I was suffocated and I went to a psychiatrist and was taking medicine for 6 months. So I decided to live in Vienna no matter what it takes.

Me: What are your negative and positive experiences concerning searching for jobs? 
Her: Negative is that you only depend on relations. The government doesn't support with that, and if it supports then, then it puts you in unsuitable place. It is only you and your relations. A lot of people are attending the language courses but not benefiting from it. They are there with their body, but not with their brain. Can you understand things when you are in psychological distress? Are you able to solve your problems in a right way? Of course not. Then there should be psychological care to this refugee and then you start to do language courses. Even for a short period. If you cannot do this, bring old Arab people into the country to help him, to be responsible for him, to lead and to tell him what he should do. And this should be done immediately, and not making him wait 5 or 6 months without anyone asking about the refugee.

Me: And was there help from Austrian NGOs concerning searching for jobs here?

Her: I have an interview with [cites institution] on the $26^{\text {th }}$. I will tell them everything I can do. From acting to theater management and to taking care of Arab kids and Arab women. I will tell them everything I can work with. The most important is to work and to get out from something that is making me [English] stress.

Me: So, you wanted to come to Vienna from the beginning, and not Germany?

Her: Even when my friends helped me to apply for the visa, it was at the Austrian Embassy.

Me: Straight to the Austrian Embassy.

Her: Yes. I didn't think about others. Despite having relatives in Sweden. They told me to go register in the camps of Lebanon and go to Canada; we have a lot of relatives in Canada. They live in those countries but there is depression. I was afraid for my children.

Me: Sure. What changed in your life since your asylum was accepted here?

Her: I felt very much safety and happiness. In that day I slept so much. I dreamed something. I felt something that made me happy which is related to [cited names], my kids. But, of course, when Syria is good, I will go back to my house. But for my kids no, because in 200 years Syria wouldn't build a future for them.

Me: I understand it of course. This is very difficult.

Her: I slept, really. I felt that I hadn't slept for more than a year. I slept happily. Thank God. When I did the passports, then I felt the real immigration. Who am I? What am I?

Me: Can you tell me, who were relevant and who is still relevant in your life here in Austria? As persons, and organizations. Of course, I don't want people's names. For example, [cites an organization] is one of them. 
Her: They benefited me in small things and went away. They got to know each other, what else can they do? And then you and your efforts. How can you build relations with your financial limitations? You are responsible for a family, so you cannot spend a lot of time [on trivial things] because you have work and [learning the] language, and everyone is busy. We feel that there is no one taking care of us. No real care, no direction to lead people towards. By the way, a lot of money is being spent, but in a wrong way. People need a system of care, in it you draw ways, pay less money and bring people to support. You bring people to support them psychologically because if not, then you cannot. I know people here, doctors at universities, are not leaving the home. They live with depression and in a weird shell.

Me: And now tell me a bit more about wellbeing.

Her: My health?

Me: Yes, but also your psychological health. First thing I want to know, how do you feel now?

Her: Well, I became psychologically depressed, knowing that I helped depressed people. In my country and in the theater, the most important play I did was for depressed children. I never expected to feel depressed. Even if I want to go to the market and buy tomato paste, I would forget even though I wrote a list. I would go back home and cry like kids. If my kid asks me to bring him something or he bought something, I would worry all night and not sleep and cry a lot. I would cry wherever I go, and I got depressed. In terms of my health, for one year I got muscle strain in all my body. I would move like a robot. And this is part of the depression. This is psychological crisis. I got tired and they asked me to do ECG for my heart. And they found that I have accelerated heart rate and I might have a surgery in the coming two months. This feeling is rough.

Me: Most of it alone? Or you talk to friends or family to manage your problems?

Her: I have no one here, no relatives. And my friends here are all the same as me. On the contrary, maybe I am more conscious than them. Even when I want to go to them, they are all busy. Even when you are at home, you should study because you are not doing well with language. And you should finish because you have things to do. Everyone has obsessions, and no one is stable and relaxed. You go and see your friends when you do fun things.

Me: And you should talk to someone who doesn't have a lot of problems so you feel relaxed. To forget a bit the problems.

Her: I want to ask someone who is strong so he can support me and not the weak.

Me: I understand.

Her: We are all weak. 
Me: To what extent...

Her: When I had depression, I didn't bring happiness. On the contrary, I tried not to meet people at all because I felt that I would give them negative energy. Every night, when my kids sleep, I feel bad. I would wake up and look at [cited a name] and take energy from here while she is asleep. And I would go to my son, sit on the bed and look into his face and take energy from him as well. I would cry a lot and the next day I get up better and stronger. I would tell myself that I should go, I should work and I should walk. When I find nothing, I would walk in Vienna's old streets, in Stephansplatz. Sit alone in a café and smoke.

Me: To breathe some air.

Her: Yes. I would get lost sometimes and ask myself where I was. I created something special for myself in the streets and cafés. Now I am good.

\section{Case Study 4-Aziz}

Aziz is 33 years-old and he is single. He arrived in Austria in December of 2015, and after a few months he had his plight to be recognized as a refugee accepted. $\mathrm{He}$ is an Alawite form Syria, and lives with a German companion in Vienna while his whole family still lives in Syria.

Me: Who are your most important social contacts in Austria?

Him: I want to say something. Before I got to know this German woman, it was difficult to get to know a girl or even a friend. This is a bit difficult. First of all, the kind of social relations here in Europe. A guy doesn't do relation with another guy. There is, but not as us Arabs, you know how friendship is between Arabs. It is as brotherhood. I go to sleep at his place, and he comes to stay at my place. We could also share a bed. We stay together. But here guys are different. If I make a direct contact with a guy, he would immediately think I am gay. I understand there are cultural differences. At the same time, when I want to get to know a girl, I faced this more than 15 or 20 times, when she knows I am from Syria, she says "Danke schön" [many thanks, in German] and leaves.

Me: Oh really? This is difficult. People you know are mostly from your country, from Syria. Or not? Do you also know Austrians?

Him: Recently, I started to get know more foreigners. 5 months earlier, I didn't know any European person. I had to deal with people from my country and especially from Latakia. 
Me: So, they were not open to you. Do you know people from Syria as well, or Arabs?

Him: Yes, I have friends.

Me: Like [cited a name].

Him: Yes [cited a name], and 2 others.

Me: Not a lot.

Him: Yes, not a lot. Four.

Me: What are the most challenges you have in your life here in Austria?

Him: Studies and language are the biggest challenges I have, and after that, work. Can I talk in details about this issue?

Me: Yes, sure.

Him: The media in Europe is making a big problem about us refugees. When we first came here, they said about refugees that they are bad and terrorists. And then, they ask us why we are not working. Who would hire us then? If you own a company, or a firm, and you always hear bad things about Syrians or refugees, would you hire me?

Me: Of course, I understand.

Him: You wouldn't. And in the end, they ask on TV why refugees are not working. So, now, work is a challenge. Language is also a challenge because we only study it at school, and cannot make contacts with people since society is refusing us.

Me: How did those expectations change after you came here?

Him: I was shocked in reality. Society kind of refuses us, and it is difficult to find a job. So, you start to give up, and ask to work in any job other than my profession. In a restaurant, or any job, to get rid of the Social and Labor Office.

Me: So, you don't like your situation with the Sozial [Austrian social welfare system]?

Him: No, I don't like it.

Me: So, you must change the situation.

Him: Exactly. I am trying to change it. I did it myself. I started going and see restaurants, and ask if they need workers. But when they know I am from Syria, then they say no.

Me: Straight like this?

Him: Yes, straight. They apologize. 
Me: I understood. What would you work with in the country, here, if you have the chance?

Him: (...) I also want to work with nutrition.

Me: What is that?

Him: Nutrition, healthy food, vegan. I am vegan.

Me: OK, I understand it.

Him: I hope to work with this in a professional way because I learned it in Syria in a professional way. Without a certificate, only experience.

Me: Which positive and negative experiences did you have when searching for jobs?

Him: Negative.

Me: Only negative.

Him: To be honest, it is negative because I got tired of looking for a job. A respectful job that respects my certificate, thinking, and my mentality. Unfortunately, it is hard here. Of course, language is a barrier here. From 5 months on, after I got to know this German woman, my language started to improve. But before, those 5 months, I didn't have good German language [skills], and work is very hard. When you want to work with something, they say go work at McDonald's. I have no problem with that, but it makes me sad. I might not work from my heart, and without loving it. I didn't study to work in another profession. It is difficult on me; I wish to work in my profession.

Me: Are Austrian organizations relevant concerning this issue?

Him: What is it?

Me: Austrian Organizations. Like [cites two organizations mentioned by the interviewee].

Him: Yes, organizations. Honestly, I don't have any contact with organizations at all. Because life has taken us here. You feel pressured to find a job and also studies. In addition to that, the depression that someone experiences when you hear the news about Syria. You stay stressed whenever you hear news about Syria, and the war there. Your stress stays every day. For a period, I got a headache. What do they call it? Migrane?

Me: Migraine.

Him: Yes, exactly. I had itfor 2 months, because of the situation in Syria, and because my family was in danger. Then, I had terrible headaches, and I couldn't sleep well because of this subject. That is why I don't have so many contacts with organizations. Plus, it is not that I lost trust with organizations, but I know 
that there are huge amounts of Syrians. So, when I go to an organization and I find 100 Syrian waiting, then I won't get what I want in short time. And my application will be ignored. There will be thousands waiting. I hope you get me.

Me: Can you tell me about the places in which you stayed here in Austria when you came? After you came?

Him: After I came, I lived first for 3 or 4 days in Traiskirschen [Austrian transit camp], and then I moved to a small pension in an abandoned village. Do you know what it means? The pension is there and the village is $2 \mathrm{~km}$ away. There is no internet. We bought internet cards that had no connection. And whenever we needed to buy stuff, we had to go $2 \mathrm{~km}$ away and come back. When I arrived, it was cold here, and there was snow. I would die out of coldness if I even wanted to buy rice. Then I moved here to Vienna. I had a friend who lived here and has a house. I lived with him for 15 days, and then I saw another house in the $13^{\text {th }}$ neighborhood. They were all Syrians. Of course, I don't want to mention that in my entire trip from Syria to Austria or even here in Austria I was exposed to sectarian situations. I have a sectarian problem here because of war in Syria.

Me: Sure. If I may ask you, your origin is...

Him: I am Alawite.

Me: Yes, that is why it is very hard on you.

Him: A lot. I go to this house, and I get cursed and attacked.

Me: They thought you are with Asad [the Syrian president].

Him: Exactly. Even if I you are not with Asad, just because you are from another sect, you face cursing, shouting, and screaming. Then I moved to a house in the $2^{\text {nd }}$ neighborhood, where I had to stay with an Algerian so I could be away from the Syrian atmosphere and the sectarian problems, and you did this in Syria.

Me: Really? Very difficult.

Him: Despite this, I am not defending, and I understand others, and I say it is $O K$. We are bad. I am trying as much as I can, and I lived with this Algerian. (...)

Me: I am sorry, dear. This is very difficult.

Him: I almost got killed a few times on the way because I am Alawite.

Me: Was it easier for you to establish social contacts here in Vienna [than in the Austrian countryside]?

Him: I thought it would be easier, but unfortunately it was difficult. 
Me: It was also difficult. You thought it would be easier, but it wasn't.

Him: I expected it to be easier, but it turned out to be difficult.

Me: Yes. Where did you feel the most part of the local society?

Him: Part of the local society?

Me: If there is such a place.

Him: Honestly, not.

Me: Do you like your actual neighborhood and neighbors?

Him: My neighbors... Vienna is a beautiful city. The neighbors in which I was in the $20^{\text {th }}$ district were very racist towards us.

Me: Even here in Vienna?

Him: Syrian or Arabic names were scary [to the neighbors]. Even though I am not a Muslim. I am an atheist. Do you know what it means? (...) I had problems with Arabs because they don't accept me as an atheist and I don't believe in the existence of God. And Europeans think I am a Muslim.

Me: Do you like your actual neighborhood and neighbors?

Him: In fact, there is so much fear from Islam (...) I understand this thing, I had shocks here. When I get refused from one, two, or three girls. There were Muslim people here, and they were not extremist. They became extremists because of the people here who refuse them.

Me: I know how it is! This is not nice.

Him: They came moderated from Syria. But when they saw that society is refusing them and not accepting to know them... I have a friend in Germany, he was very moderate in Syria, do you know what moderate means? He is not extremist, but he became an extremist after he came here. I asked him why, and then he explained that he faced some situations, and they cursed him and they spoke badly to him. I talked to him, and relaxed him, and explained to him that he has to understand others. If others are thinking something about you, you should accept it. Show him that you are very nice.

Me: Sure. Are there relevant organizations or people for you from here? I don't want names.

Him: Organizations or?

Me: Persons. Maybe this German is very relevant for you here. Persons and organizations.

Him: I don't have contacts with organizations at all, and as persons only this German woman. She is basic in my life. 
Me: In what context were those people relevant for you? For example, you said with this woman?

Him: Yes. Honestly, with this woman and my new work. I don't have other contacts.

Me: In what context is this contact important for you?

Him: In what place?

Me: In what context? Is it a hard question?

Him: It is not hard.

Me: For example, concerning living your social life. Or there was help concerning work or studies.

Him: To be honest, the first thing I had is emotional stability. Because for me, if I don't love, then I cannot live with a woman. Some people might live with a woman to learn the language.

Me: This is also important.

Him: It is important. But my priority is to love a woman, and after, I learn the language. I am honest with myself to the point that I cannot live with someone if I don't really like her. Love comes first with me, and then interest. And if I don't love, I don't learn.

Me: I want to know more now about wellbeing. I mean physical health, and psychological health. How do you feel now?

Him: More than happy now, but I had depression for one and a half years, because of the question of integration here. Plus, the situation in Syria was very bad. So, I was psychologically very tired. Bombs here and there, and I was feeling always in stress. I have 10 friends who died in Syria. Every month, I hear that a friend died, and I feel more depressed. Families are lost, and I don't know anything about them until now. This caused a lot of depression. Now the situation is better, politically. It is safer now, and there is not a lot of Islamic state [ISIS] as before. All this, also with me getting in contact with this woman, made me feel more comfortable.

Me: I am sorry, this is very hard. I don't have words, but I know it is very hard.

Him: Thank you.

Me: What is bothering you?

Him: Bothering me here in Austria?

Me: In Austria or outside, in your life in general.

Him: The war in Syria, and politics. The problem is that I read politics very well. When I see what is happening all over the world, and how all the world is playing in Syria, this troubles me a lot. These are a lot of lies in the media, 
and you know the truth, this makes you stressed. All that is happening is lies. This is what bothers me the most also here in Austria. It is bothering me when people are not integrated with you. Some people think that we came here to bother them, but we came here because we were obliged. I could do my Ph.D. in Syria and be a professor in this university. Why would I come here to work in a restaurant? I am starting from zero here. I see this as very hard.

Me: Sure. Do you feel positive in this country?

Him: For 5 months. I don't know what to say; a bit when you find someone who helps you in this country, and then you will feel positive. But when you see that everyone is staying away from you, and everyone doesn't want you, and doesn't want you to work for them, then you will feel negative and psychological pressure. Now, I got to know my friend, who accepted me, and is making jokes with me in the building, for example. Then, you feel that life is beautiful here.

Me: I understand. How do you manage your problems?

Him: Only with a smile. (...) Every problem I have, I try to analyze it, understand it and see it from more than one point of view. It takes time. (...) Like some time ago, there was a person in the U-Bahn [subway system in Vienna], he saw I looked like an Arab and that I was talking with my sister in Syria. I was speaking Arabic on the phone. He started to curse me and hit my glasses. He started shouting and asking "what has brought you to this country?" He is with Strache and Kurtz [Austrian politicians]. And then, when I was leaving, I thanked him and say "bye bye." After that, I started to understand him. The media here is showing him that Muslims here are this and that. If I was from this country, if I was Austrian, I would behave like him.

Me: You would of course be angry.

Him: Fanatic, not angry.

Me: Do you receive help from close friends when you need it?

Him: No, I create happiness from inside.

Me: Inside yourself?

Him: I create happiness from myself.

Me: For example, you don't talk to your family about those problems.

Him: I talk to my mother every day, so I know what is happening with them. You know they are in a war, and it is a must to make daily contact with them. But, believe me, when I entered the depression, I helped myself to go out of it. As for happiness, I try as much as I can. If there is a depression atmosphere, I try to create a smile and a laugh, and this is an obligation. This is a must - we cannot continue our lives depressed. 
Me: And now, how do you feel about Austria and Austrians?

Him: I feel that they are scared from us. I might justify it, but I like and respect them because it is not easy - a country with not so many refugees and suddenly comes this large amount. And they are taking money from the Sozial [Austrian social welfare system], and accepting people easily. I respect that there is a large number of people who said "yes". I feel so happy when I see people going on demonstrations with refugees, as respect for refugees. I will be honest, and will say it, Austrians are a lot more respectful than us Arabs.

\section{Case Study 5 - Faisal}

Faisal is a 39-year-old man of Palestinian origin, but born in Syria, who arrived in Austria in April of 2015 and was later recognized as a refugee. In Syria he married another Palestinian refugee from Syria and he's a Sunni Muslim.

Me: What is changed in your life since you got your asylum papers? For example that you were working, I don't know.

Him: No. I was not working or studying. We were living in the camp. A teacher used to come as a volunteer to give us classes. But you were not psychologically stable because you were not recognized for asylum. When I got my papers, I felt psychologically stable and started to have a help from the Sozial [Austrian social welfare system]. Of course, back then my family was in Turkey and they needed to pay the rent and there was no one to support them economically, so I would send [money] to them. So, there was some kind of stability so I would save my family in Turkey and help them.

Me: Now we will change the subject. We will talk about public health. How do you feel not only in terms of your body but also psychologically? How do you feel now?

Him: Yes, not only physically but also psychologically, I feel better.

Me: But are you sad as well or not?

Him: It is not I am sad, but it is the social life that I lost, just that.

Me: What are the things that affected your feelings about your career? (...) What is important in your life?

Him: What affects my life is that, as I told you, there is no social life here. Kids are comfortable going to school and benefiting and improving, going forward until they get to their Austrian friends. So, this is not affecting me. My wife is suffering because of the absence of social life, nobody is coming to visit. 
Me: Only for her or also for you?

Him: For her and also for me. For me it's easier. I see my friend and I have colleagues at work but my wife does not. My friend's wife, for example, if they get close to each other, but this is only one. Not more.

Me: How do you feel about your future here in Austria? What is the importance of your relationships concerning this subject?

Him: With the most troubles I got and whatever happened with me I used to go back to talk to the old generation.

Me: What do you think Austria should do so you can have a better life?

Him: I think what they should do is to make the conditions or rules for the nationality easier because it's very difficult especially for us staatenlos [German for stateless]. I mean we don't have a homeland, I was already a refugee in Syria and came as a refugee here. This question is psychologically very hard on me. My Dad was a refugee and I lived my life in Syria as a refugee, so most of my life I have lived as a refugee. So, I wish that my kids would get the nationality.

Me: And your wife is a Palestinian refugee?

Him: Yes, I told you we used to live in a gathering and we were all refugees.

Me: What do you think the main steps are to settle down in Austria?

Him: My first priority is that job opportunities get easier.

Me: Before the language?

Him: For me, as I toldyou, it is going at a good pace. But it is important for my kids. Maybe my children are better than me with language but they are still not at the level to continue their studies. There are levels for language. For me it is to find a job opportunity which is easier than this and in the field I like. For my kids, no, the language is the most important because they need the language so they can keep going with their studies.

\section{Summary}

These interviews show a general awareness about psychological problems relating to displacement and adapting to a new reality mostly associated with insecurity. Even those reporting the effects of such problems in their own bodies still tended to define these problems as psychological effects of instability, crisis, or distress. 
Leyla reports feeling estrangement and disenfranchisement (ghurba), and depression ( $\left.k a^{`} a b a\right)$, which she defines as a psychological problem that may not have a solution. Depression for her is an illness causing her to feel helpless, and which made her look for a doctor who tried to control it via medicine. But what she is feeling, disenfranchisement, cannot be solved by taking medicine, in her opinion. She expresses feeling "brittle inside"; powerless, without capacity (qudra) to go out of her house and interact with people or even to read, which she mentioned as one of the meaningful things in her life. Thus, she feels lonely (wahida) and detached from her reality in Vienna. In her powerlessness, "her brain stops," and she looks for things to motivate her, finding it in her grandson, who gives her "energy" (haluya). All of this makes her long for her life back in her country, where she ultimately wishes her life to end. That is, taking back her old life in her country is the ultimate solution for her problem. Hence, while this does not happen, her psychological illness may not have a solution.

Zara also reports that sometimes she feels that "no one knows her" (majhula). She is estranged. When she has things occupying her mind, she is able to drive her thoughts away from her situation. But when this does not happen, she feels estranged. She says that herself and her friend got depressed by stating literally that they are "psychologically tired" (nafsiaty ta'abane); that is, without strength to engage life. The term she chooses in English to express this state of mind is "depression." She further expresses feeling estranged by stating that everyone is different than her. She is, in her words, "unique." She also expresses being "psychologically tired", or depressed, as being "sick and tired of being labeled as a refugee."

Habiba's biggest challenge in Austria is to prove her own existence. Hence, she also feels estranged - detached from reality - as she reports her individuality, thus her "humanness," lost by being treated "as a number" among other refugees. This caused her to feel suffocated (akhtanaqa), without breath, which led her to find a psychiatrist who gave her medicine. She expressed her state of mind as being in psychological distress (dughut nafsya) and in a psychological crisis (azma nafsya), which logically prevents her from solving her problems on her own. When talking about her relatives in Europe, she mentions that they also live with depression (ka'aba), without care (hadan). Likewise, other people she knows in Austria are also depressed (ikti $\bar{a} b$ ), living "in a weird shell" (qawq'a gharibya), that is, in relative isolation. She attributes these symptoms to her being psychologically depressed (hâly nafsya iktā'bat), aggravated by having helped depressed people (makt 'bin). During this time of distress or crisis, she avoids meeting people so as not to give them "negative energy." Her depression led to insomnia and crying wherever she went. She also had generalized muscle strain. Like Zara, she found comfort in her family - this time in her son, from whom, in her words, she would take energy while he slept. Whenever she would be out of her house, she would feel lost.

Aziz feels that Austrian society refuses him. He thinks this refusal is understandable (he does not feel entitled to work as a foreigner), but it nonetheless saddens him (bhazany) and he may not engage this context "from his heart" (min qalby), but out of pressure 
(dghut). The ongoing situation in Syria leads him to feel depression (ikti'āb) and stress (bi-stress). He reports having migraines for 2 months straight, which prevented him from sleeping. He also feels disenfranchised in Austria, and that he does not belong in this country. Nonetheless, when he found a woman to be his companion in Austria, he also felt emotional stability (istiqrār bil-'âtife). This took him out of his depression (ikti ${ }^{`} \bar{a}$ ), which he attributed to the question of integration (indimāj) in Austria. He referred to depression also as feeling psychologically tired (nafsiaty t'abane), and to experiencing stress (bi-stress) and feeling troubled (biz'aj) as bombs fell in Syria. When his friends died, he got more depressed (ikti ab akthar). As he settled down in Austria with his life-partner, he felt more comfortable (mirtah). When he felt that no one was helping him in Austria, he felt burdened (literally, psychological pressure - dghut nafsy), but after being with his companion, he feels he could create "happiness from inside" (min juwa) himself. He felt he needed to drive happiness form inside because he didn't want to burden his family and friends who are already under much pressure in Syria. Nonetheless, he still feels relatively disenfranchised in Austria, since people are "scared from them"6 (khaif minna).

Finally, Faisal expresses not feeling psychologically stable (mustaqar nafsyan) while not recognized as entitled to asylum. Only after his official status changed from asylum seeker to refugee and he got financial help from the Austrian social welfare system did he feel psychological stable. According to him, his wife is still suffering (bta'an) from the absence of social life, as she has no friends and no one with whom she can talk in Austria. The question of refugeeness is psychologically hard on him and his family (kthir sa'ab 'aleyna, nafsyan), because his father was a refugee himself and Faisal lived his whole life as a Palestinian refugee in Syria.

The above expressions of wellbeing or lack thereof appeared in at least half of all the interviews we conducted among Syrians and Iraqis through LODA. As for the other half, one cannot take the lack of expression of psychological distress simply as its absence from reality. While it is logical to conclude that some did not feel psychological distress, it is also logical to conclude that many simply did not feel comfortable enough to share these issues with the interviewers, or were unaware of such issues or interpreted them differently. Yet, such expressions presented in these 5 cases are much more general in the interviews. For example:

Amina is a 56-year-old Syrian refugee who arrived in Austria in June of 2016. She is of the Druze faith and lives in Vienna with her husband and her daughter. When asked about the main challenges of living as a refugee in Austria she mentioned: "It creates psychological distress [azma nafsyia]. I mean, wherever people were happy [before displacement] there will be ghurba, ghurba for the nation, ghurba for the family, work, friends... this."

6 In the interview, "us" meant at times "the refugees" and at other times "the Muslims" or the "Syrians." 
Anis is a 53-year-old Syrian man, Sunni Muslim, who arrived in Austria in October of 2015, and has been living in this country as a refugee with his wife and children. When asked about his plans for the future he responded:

I hope to find myself. To gain engineering skills, architectural skills. So, I could do something one day. Because a human always has dreams to do something. Especially me, as an architect, I always find myself with it [a dream]. If I have a chance, I would work, if not here, maybe if I go back to Syria.

Adil is a 30-year-old Sunni Muslim man from Iraq. He is single and lives in an apartment that he shares with two other roommates, one from Sub-Saharan Africa and the other from Germany. He arrived in Austria in May of 2014 and was granted asylum, unlike most other Iraqi asylum seekers. He stated:

My health is good, but I am psychologically exhausted [madghut nafsyan]" (...) Sometimes, I feel very motivated [muthamis] and I did the Praktikum, and finished the language [course]. And sometimes, I feel drained [muhbat] and feel that nothing is going to happen (...) about the difficulties we as refugees are facing in this country. There are positive points, but it is good to show the world how we are in pain [waja'] from some issues. Let them know I am a stranger in this country but I am not a monster.

Najib is a 32-year-old Syrian Sunni Muslim whose wife is still living in Syria while he was granted asylum in Austria. He has been trying to bring his wife to this country, and when asked about how he was doing psychologically, he answered me:

"I'm a bit tired [shway t'abān]. Some days there is pressure [dghut] to work, so I feel a bit tired psychologically [t'abān shway nafsyaty]. Also because of my family, and the situation in Syria. These kinds of things."

Melhem is a 33-year-old Syrian refugee who is married and arrived in Austria in May of 2015. When asked about his main challenges in Austria, he answered: "Work and language, for me, are everyday problems. I think about them every day, my wife knows. It an influence on my mind [m `ithir 'ala nafsiaty]." And when asked about his expectations about living in Europe, he replied: "when we were living in the [transit] camp [in Austria] we were psychologically tired [nafsyaty ta'abana] and sad a lot [hazinin jidān], but then when we met the Austrian people, to get the residency, our expectations changed in a positive way." Then, when asked about what changed once he got his refugee status, he told me: 
All of us in the camp, I mean, we didn't sleep. Even an identity we didn't have the luxury to possess. Do you know? No rights, or something else, never. These papers you get, you feel that you have value, I mean, you can go, you can travel if you want, you are stimulated [tahafaz].

And when asked about how he felt at the time of the interview, he answered: "But the problem is I am depressed [nafsyaty ta'abana] in what relates to work. I need to work quickly. I need it around me.”

Iskandar is an Iraqi refugee. He is 29 years old and is Sunni Muslim. When asked about his experience living in the Austrian countryside and in Vienna, he answered me:

I have 2 friends living in villages here, they are now in psychological crisis [azma nafsyia]. And they started going to doctors for treatment. Their case reached a dangerous level. It is very difficult to come from Syria and live in a village (...) it is impossible for me to live in a village. Maybe if I was obliged to live in a village, then I would have returned to Syria. I couldn't continue. Or, I would have a psychological illness [ma'anna nafsya] as my friends. It is impossible to live in a village. In Vienna, somehow there is movement, you can see friends, and you can get to know people. Especially in capitals there are lots of foreigners. You can find them, and get to know them, but village society all over the world is a closed society.

Awad is an asylum seeker from Iraq. He is 23 years old and identified himself as being Muslim. When asked about if anything was troubling him, he answered:

Actually, yes, the question of whether I am allowed to stay here or not. Because then, whatever you build you can lose in the blink of an eye. And then, the family. When you remember the family, when you remember them, what happened, and where they are.

And when asked about how he solves his problems, he replied: "My family is the most important thing in this regard. When I hear the voices, I become happy. And this helps when I'm psychologically tired [nafsiaty t'abana]." And when asked about to what extent he felt motivated, he replied: "Not much. Everything in my life now is to listen to German and learn German so I am motivated to get my degree in B2. If there is no German then I go to sleep in my house."

To give one last example, Alyiah is Syrian Druze. She is 26 years old and is married. When prompted to reflect on what changed since she got her official status as a refugee in Austria, she told me: 
Many things. I could have a passport, apply for a job, I mean, enough; my residence is here for 5 years and hopefully I will renew it. There are some fears, maybe it doesn't get renewed and we have to return. But now we have security, I am comfortable [nafsy raha - literally, my self is comfortable]. My mind [nafsiaty], enough, my passport is Austrian, that one they gave, so it changed many things I want.

\section{Language, Power, and Belonging}

As the case studies show and the excerpts above reiterate, Arab displaced subjects have expressed what the mainstream Austrian medical discourse would call "depression" in many different ways - mostly (if not all) variations of the underlying principle that depression is a lack of power to act upon one's own life. This power is conceived as emanating from one's self, radiating from the subject and powerfully affecting those around it. Steering away from negative environments can help curb depression, and staying close to beloved ones is healing. However, psychological mood radiates from every self, so some interviewees chose to avoid their family and friends in order to not affect them negatively, even though they would benefit from the contact.

This general conception does not seem so different from European popular conceptions of mood, including depression. According to this perception, energy, motivation, stimulation, power, capacity, and comfort are opposed to psychological fatigue, depression, stress, helplessness, loss, incapacity, powerlessness, and discomfort. Characteristic of the experience of forced migrants is the role of language as barrier or bridge. And what is perhaps unique to Arab-speaking forced migrants' expressions is the centrality of the idea of "fatigue" and the framing of disenfranchisement through the concept of "ghurba."

Thus, disenfranchisement is seen by the interviewees as their main problem, which is caused first by displacement but then also dynamically maintained by the lack of engagement with the host society, either by the lack of opportunity or by the subject's own lack of power to do so (and usually a combination of both). This lack of engagement is seen from the point of view of most interviewees as deeply connected to language competence, especially among more senior subjects who overwhelmingly have strong difficulties learning German.

Language (and cultural) competence does not only affect the displaced Arabspeakers' capacity to understand the Austrian context, for it also affects the Austrian capacity to understand my interviewees. Language is not merely a question of translation to equivalent terms, but it informs and organizes conceptions and affect. Yet, conception, affect, and thus experience are also not completely inscribed in words. The words "power," "capacity," "ability," and even "vigor" and "energy" in English, for example, 
appear confounded in the Iraqi and Syrian Arabic dialects expressed by my interviewees through the terms " $q w a$ " and "qudra." That is, whatever term I would choose to translate when one of my interviewees mentioned it would alone fail to encapsulate the full meaning of these person's expressions, which can only be understood in context. Thus, presenting the reader with the 5 case studies above is important to provide the proper context for interpretation. In this case, what has been overwhelmingly expressed by my interviewees is a lack of capacity, power, vigor, energy, and, ultimately, motivation to engage life as a refugee. Hence, the common expression of being "psychologically tired" must be understood in this context as an expression of depression.

Depression ( $\left.k a^{\prime} \mathrm{aba}\right)$, however, is not framed by my interlocutors as an objective Western medical term, but is rather understood as having different levels. That is, one can be more or less depressed, just as the term is also colloquially expressed somewhat commonly in Europe. Similarly, being stressed is either expressed by my Arab-speaking interviewees through borrowing the term from English (bi-stress) or by the term "pressure" (dghut). This equivalence, coupled with the tendency of many interviewees to underestimate their psychological distress (either to gain control or to not appear helpless), leads me to understand that being stressed often means here being severely depressed.

Overall, while wellbeing may be best translated in Arabic as 'afya (health) as both the English and the Arabic terms potentially address not just the body but the psyche, my Arab-speaking refugee interlocutors have been expressing what Europeans call depression (and even trauma) in different ways. These entail different overcoming strategies rather than identifying these as symptoms of illness and turn to medicalization. While a few of my interlocutors expressed having psychological distress or crisis (azma nafsya) or depression $\left(k a^{`} a b a\right)$, many others expressed (ghurba), which in this context, among other things, means feeling disfranchised, having their selves tired (nafsy ta'abana) or being psychologically tired (nafsya ta'abana), and being without capacity/power (and in this case, motivation) (qudra; qwa) to act upon their lives and upon the world. The term "settlement" in Arabic (istqrär), is associated with habitation and residency, but also steadiness (in this case, security) and agency (as the root of the term implies decision, or resolution). Therefore, feeling powerless to act, being psychologically tired, or being disenfranchised greatly affect my interlocutors' chances of feeling settled in Austria. These feelings of being settled (or not) are the counterpart to what in turn has been discussed in Europe under the rubric of "integration" (in Arabic, indimāj). If "integration" is a two-way route, as it has been expressed by Austrian official documents and among humanitarians in general, then understanding how Arab-speaking refugees understand, express, and manage wellbeing becomes imperative research. 


\section{References}

Dodge R., Daly A., Huyton J. \& Sanders L. (2012), The challenge of defining wellbeing. International Journal of Wellbeing, 2 (3), pp. 222-235. < doi:10.5502/ijw.v2i3.4>

Huber M., Knottnerus A., et al. (2011), How should we define health? BMJ 2011;343:d4163. $<$ doi: $10.1136 /$ bmj.d4163>

LARSON J.S. (1996), The World Health Organization's Definition of Health: Social versus Spiritual Health. Social Indicators Research, 38 (2) (Jun., 1996), pp. 181-192.

Reber A. ( 1995), Dictionary of psychology - Second Edition. Harmonsworth, Penguin.

RYFF C. \& KeYES C. (1995), The structure of psychological well-being revisited. Journal of Personality and Social Psychology, 69 (4), pp. 719-727, retrieved from $<\mathrm{http}: / /$ dx.doi.org/10.1037/0022-3514.69.4.719>

SAHLins M. (1972), Stone Age Economics. Chicago, Aldine Atherton.

WHO (ed.) (2006), Constitution of the World Health Organization, retrieved from $<$ www.who.int/governance/eb/who_constitution_en.pdf> 